\title{
Vestígios do sonho português no sudeste asiático
}

\author{
Pierre Guisan \\ Universidade Federal do Rio de Janeiro
}

RESUMO: A PARTIR DOS TRAÇOS QUE SOBREVIVERAM DA EPOPÉIA RELATIVAMENTE BREVE DE PORTUGAL NO SUDESTE DA ÁSIA, TRAÇA-SE UM QUADRO DO "SONHO PORTUGUÊS" NAQUELE ESPAÇO.

ABSTRACT: THE "PORTUGUESE DREAM" IN ASIA: A BRIEF EPIC

PALAVRAS-CHAVE: PORTUGAL E O ORIENTE, MALACA, KRISTANG, LÍNGUAS EM CONTATO KEY WORDS: PORTUGAL AND ORIENT, MALACA, KRISTANG, LANGUES IN CONTACT 
s armas e padrões portugueses postos em África e em Ásia e em tantas milhas fora da repartição das três partes da terra materiais são e pode-as o tempo gastar; pero não gastará doutrina, costumes, linguagem que os Portugueses nestas terras leixarem."

João de Barros. As décadas da Ásia

\section{O naufrágio de um sonho}

No ano de 1511, uma catástrofe abalou a expansão além-mar de Portugal, que até então triunfara sem derrota ao longo da sua conquista de estabelecimentos no Oriente. A nave-mor da frota de Afonso de Albuquerque afundava com a sua carga preciosa perto da costa pantanosa de Sumatra, do outro lado do estreito comandado pela orgulhosa cidade de Malaca, da qual os portugueses acabavam de tomar posse. O mar engoliu com o navio o imenso tesouro dos sultões de Malaca, um dos portos mais ricos do universo. Não há inventário detalhado do conteúdo da carga, entretanto sabemos que era de uma riqueza inacreditável, um tesouro sem igual na história.

Malaca: na alvorada do século XVI era provavelmente o maior porto do mundo de então, superando até Veneza. Escala obrigatória onde a navegação à vela espera a inversão anual da monção, em Malaca se encontram marujos e comerciantes, chineses, malaios, árabes, indianos; nos cais, nas ruas e nas vielas podem ser ouvidos dezenas de idiomas, porém dominava um pidgin de base lexical malaia, o bazar melayu, do qual uma variante crioulizada, o baba malay, sobrevive hoje na comunidade peranakan, de atuais descendentes dos comerciantes chineses da época. Dividida entre facções políticas, enfraquecida militarmente, cobiçada e traída pelos ambiciosos, a cidade pôde dificilmente resistir à determinação desse punhado de bárbaros aventureiros conduzidos por Albuquerque.

Após a fuga do Sultão de Malaca (que se refugiou no Sul da península, onde fundou a cidade de Johore Bahru, em que sua família continua reinando até os dias de hoje), os portugueses pretendem controlar o comércio nessa parte do mundo e, em particular, o negócio altamente lucrativo das especiarias, que agregavam um grande valor num volume restrito. Infelizmente, a partir de então, o empório de Malaca inicia a sua decadência, instalando-se numa so- 
nolência da qual nunca despertaria. A falta de habilidade daqueles ocidentais, que continuavam atuando como se ainda estivessem na época das Cruzadas e que pretendiam impor a sua religião à força, não podia conviver com as leis do comércio internacional. São os árabes que, pela sua tolerância e ao mesmo tempo sua insistência de mercadores, vão difundir a sua religião. Assim, o islamismo vai progressivamente suplantar o budismo, o hinduismo e o animismo indígena. Esses mesmos mercadores árabes conseguirão inclusive impor o termo pelo qual, desde os tempos das Cruzadas, designavam os cristãos: são os franqui, hoje ferenggit ou perenggit em malaio, e farang em tailandês.

Importa, com efeito, frisar a ambigüidade do empreendimento português. Se a sua motivação óbvia era vinculada à vocação comercial de um pequeno povo sufocado por uma terra ingrata com grande fachada oceânica, outras causas de natureza ideológica sem dúvida tiveram um papel poderoso e constituiram fontes inesgotáveis das quais a psicologia coletiva tiraria a energia necessária para a aventura exaltada por Camões. Assim, a "reconquista"1 pelos portugueses das terras do Sul da Europa dominadas até então pelos mouros como Lisboa, Alentejo e Algarves - prossegue além do estreito de Gilbratar em direção a esse outro Algarves - "al-Gharbi", isto é, o Ocidente - que é o Maghreb $^{2}$ de Ceuta, da costa atlântica do Marrocos e, gradualmente, vão daí para toda a costa ocidental africana. Em seguida, dobrando o cabo da Boa Esperança - ou cabo das Tormentas -, subindo pela costa oriental da África e singrando através do oceano Índico, os navegadores lusos [vão] se estabelecem no litoral da Índia, da península e do arquipélago malaio, antes de ancorar nos portos da China e do Japão.

Seria um engano ver neste imenso périplo a realização de aspirações meramente mercantis; afinal, os aventureiros são movidos também pelo orgulho e convicção de que Portugal é chamado a se tornar uma Nova Roma, cujos limites são os do Universo, com um novo César que será o próprio Cristo. Já se comentou muito a respeito deste traço da "alma" portuguesa, reunindo

1 Retomei aqui o termo consagrado de reconquista, apesar de ciente da ambigüidade ideológica de uma palavra cunhada pela Renascença triunfalista católica.

2 Nota-se que as palavras Algarves e Maghreb derivam da mesma palavra árabe al-gharb, isto é, o ocidente, sendo que maghreb, com o prefixo ma-, significa literalmente "o que está no ocidente". 
pragmatismo mercantil e nostalgia pela grandeza perdida, o botequim e a saudade.

Porém, voltamos à nossa nau, "Frol de la Mar". A fatalidade quis que ela carregasse os tesouros pilhados de Malaca, de um valor incomensurável. A lembrança desse "Titanic" precursor permanece na memória da região. Uma réplica - um tanto kitsch - da nau foi reconstituída na boca do rio de Malaca, onde as autoridades instalaram um museu naval. Até mesmo um convênio foi assinado entre os governos da Malásia e da Indonésia, para estipular a partilha dos tesouros, no caso, bastante improvável, de descoberta e recuperação da nau afundada. Mais uma fatalidade, porém, fez com que o naufrágio tivesse ocorrido em local de fundos marinhos constituídos de centenas de metros de lodo, o que torna certamente impossível qualquer tentativa de busca bemsucedida dos restos do navio. Porém, de vez em quando, as redes dos pescadores malaios - ou de Sumatra - voltam com moedas de ouro ou de prata, com estatuetas barrocas, destroços preciosos ou sem importância, que entretanto testemunham a era em que os portugueses mandavam na região. Com efeito, o estreito de Malaca é uma das regiões marítimas com a maior concentração de naufrágios no mundo.

Além desses destroços materiais, esse período deixou também rastros culturais e lingüísticos em terra, que em conjunto representam testemunhos atuais do sonho imperial português. São precisamente esses vestígios que queremos evocar aqui.

\section{A situação atual}

Não se trata aqui de fazer um levantamento exaustivo de todos os rastros deixados pela aventura portuguesa nessa região do Sudeste Asiático. Tal investigação, aliás, teria que ser empreendida, apesar dos poucos meios de que se pode dispor, face à urgência da tarefa: com efeito, os vestígios vão se apagando com rapidez, numa região que sofre hoje em dia transformações brutais.

Malaca, a antiga capital cosmopolita da região no século XV, continua sendo o centro da herança portuguesa nessa parte do mundo. A comunidade kristang conserva a sua língua, o papiah kristang, assim como a sua religião, o catolicismo. Embora os membros da comunidade, na sua maioria, se considerem como 
descendentes dos portugueses, tal convicção deve ser vista com circunspeção. Podemos ter certeza que, após a rendição de Malaca aos atacantes holandeses, os súditos foram todos levados de volta para Portugal, ou para outras terras do Império. O mais provável é que os kristangs se originem dos mestiços e dos malaios aculturados e convertidos.

Parece-me importante frisar tal fato para destacar a originalidade da cultura kristang, que não consiste numa mera excrescência portuguesa esquecida e abandonada à própria sorte, mas na resultante original e nova de uma mestiçagem cultural antiga. $\mathrm{O}$ mesmo acontece no que diz respeito à língua. $\mathrm{O}$ kristang não é um dialeto português - assim como o português não é mais uma variante do latim - : trata-se de uma língua no sentido pleno, cujo sistema se diferencia radicalmente da estrutura do português; porém, é dele que tira a maior parte do seu léxico. Admite-se geralmente que o kristang apresenta todos os traços que dele fariam uma língua crioula, embora tal afirmação fosse merecedora de um debate bastante amplo, que não cabe abrir aqui.

Até hoje, Malaca permanece uma cidade formada por um admirável conjunto étnico, que conjuga línguas, religiões e tradições de culturas diversas, populações que se acotovelam e trabalham juntas, porém pouco se misturam. São malaios, chineses de origens - logo, de línguas diferentes -, indianos, cingaleses, tamules, baba-nyonyas, eurasianos, e por fim a comunidade aqui nos interessa mais particularmente, os kristangs. Mesquitas, templos chineses, igrejas católicas ou protestantes, templos hindus, pontuam a paisagem religiosa desta cidade de dimensão relativamente modesta, já que conta com pouco mais de 300.000 habitantes. A população kristang, cujo recenseamento exato é difícil estabelecer ${ }^{3}$, ficaria em torno de 2000 pessoas, portanto, uma minoria que seria quase insignificante se não fosse o cuidado particular com o qual vem sendo tratada pelas autoridades políticas atuais, malaias e muçulmanas ${ }^{4}$.

Entretanto, essa comunidade teve sempre como contrapartida uma diáspora importante, desde a queda de Malaca nas mãos dos holandeses, nos anos

\footnotetext{
3 Entre outras dificuldades, há o fato de que muitos indivíduos dominam de forma imperfeita a língua kristang, e que nada é mais difícil do que estabelecer com exatidão o perfil identitário de uma pessoa. 4 Com efeito, num país sobre o qual sempre paira a ameaça de conflitos religiosos e / ou raciais, os kristangs representam o álibi da política multirracial da qual o governo federal autoritário se vangloria, sem que tal minoria possa representar um perigo pelas suas reivindicações para a estabilidade do Estado.
} 
1640. Na época, grande parte da população havia sido dispersada, mandada como mão-de-obra escrava para Batávia, a atual Jacarta, na ilha de Java, ou refugiada para fugir do protestantismo imposto à força pelos novos donos. Cabe lembrar que a Europa desta época estava ainda em pleno período das trágicas guerras de religião. Esses refugiados se espalham do reino de Sião, atual Tailândia (Phuket, Ayuthaia e depois Bangkok), às ilhas mais longínquas da Sonda (Timor, Flores, entre outras), passando pelo Norte da Malásia atual, em particular na ilha de Pinang, onde contribuem para a fundação da cidade de Georgetown, no local chamado hoje de Pulau Tiku (Ilha do Rato). Tal tendência à emigração se mantém até hoje, de modo que encontramos comunidades kristang em todas as grandes cidades da península malaia, em particular na capital Kuala Lumpur, assim como em Singapura e também na Austrália, sobretudo na cidade de Perth.

Os kristangs da diáspora continuam mantendo fortes laços afetivos com Malaca. A sua cultura e a sua língua os distinguem no seio das associações eurasianas nas quais são geralmente membros muito ativos. Entretanto, em razão da fraqueza numérica relativa dessas colônias dispersas, a sua identidade cultural depende cada vez mais de um folclore bastante afastado do seu modo de vida e das suas preocupações cotidianas. Os casamentos com parceiro não-kristang são de longe os mais freqüentes, o que contribui para a extinção paulatina da identidade comunitária.

Tal situação se repete também em Malaca, onde, apesar dos esforços de um punhado de militantes, não se pode ver razoavelmente sob bons auspícios o futuro da língua e da cultura kristang. Desde o século XIX, as famílias mais abastadas se identificavam com o colonizador britânico, ao assumirem cargos de responsabilidade na administração. Para os filhos, adotaram uma educação baseada no modelo inglês, de modo que a língua inglesa se tornou o veículo lingüístico obrigatório entre as diversas comunidades étnicas da Malásia. Hoje em dia, o sistema adotou os valores nacionalistas da Malásia, de modo que o bahasa melayu, língua oficial da administração e do ensino, já ocupou o lugar que antes era do inglês.

O turista de passagem em Malaca corre o risco de assistir a um espetáculo um tanto degradante de danças portuguesas, no local chamado de "Portuguese Square", do agrado dos turistas singaporeanos e chineses. Tal "folclore" só foi introduzido após a Segunda Guerra Mundial, por padres portugueses, e 
com certeza não tem nada a ver com o que constituiria um autêntico folclore kristang (ao passo que alí existe uma manifestação autêntica da tradição, uma dança de casal muito antiga, o branyo). Tais fatos só contribuem para a perda da identidade cultural da comunidade. Há entretanto um outro traço importante da cultura kristang que vale a pena mencionar: trata-se da culinária, rica de tradições mescladas, resultando das mais variadas influências, o que sem dúvida constitui um aspecto considerável da vida dos kristangs, que dão muita importância à boa comida.

\section{A “catástrofe” de Malaca e a diáspora histórica}

A diáspora que resultou da emigração mais antiga, a que ocorreu no século XVII, perdeu há muito tempo a memória dos laços que a unia com Malaca. Porém, a língua crioula dos exilados se manteve e tal persistência se deve provavelmente ao fato de que existia um pidgin comercial de base lexical portuguesa, que dominava a região até o início do século XIX. Pode se dizer que essa língua representava um pouco o papel do inglês de hoje nas transações comerciais da região.

Possuímos muitos registros que comprovam tal situação. Talvez baste lembrar que os missionários holandeses, antes de empreender a sua tarefa de evangelização no arquipélago da Insulíndia (isto é, a Indonésia de hoje, então chamada também de Índias Holandesas), eram obrigados a aprender o idioma português, conforme os regulamentos da Companhia das Índias Orientais Holandesas. O mesmo ocorria com as Missões e as Companhias inglesas ou dinamarquesas. Os tratados políticos, militares, comerciais ou religiosos entre europeus e autoridades locais eram redigidos em português, fossem eles assinados pelos reis de Ceilão, de Sião, ou por sultões malaios.

É curioso constatar que essa "língua franca" continuou em uso muito tempo depois da expulsão dos portugueses da região. A “língua de ninguém”, ou seja de nenhuma das partes em presença, pôde justamente se aproveitar deste status para ser adotada por elas.

Apesar de aqueles europeus conservarem por mais tempo Macau e Timor Leste, a sua presença comercial se tornou insignificante, na medida em que Portugal concentrou os seus esforços na exploração comercial do Brasil e da 
África. A existência de uma língua de tipo crioulo de base lexical portuguesa é atestada até o início do século XIX em Batávia, onde ainda constituía um meio de comunicação doméstica entre os membros da família dos colonos holandeses e os seus criados indígenas.

Tal permanência de uma "língua franca" durante mais de três séculos explica provavelmente a sobrevivência de uma língua crioula minoritária como o kristang, apesar de desprovido do suporte da língua que havia lhe fornecido o material lexical. Trata-se, portanto, de um caso relativamente raro de uma língua crioula que perdeu qualquer contato com a língua-base, enquanto a maioria dos outros crioulos convive com a presença de uma língua-base com a qual formam um continuum sociolingüístico; a língua se beneficia de um status privilegiado, sendo geralmente língua oficial, pelo menos língua da elite da sociedade. Uma das conseqüências decorrentes da situação peculiar do kristang é, logo de saída, a inexistência desse continuum, no sentido descrito pelo lingüista Bickerton ${ }^{5}$, que se estende de um basileto ou crioulo "puro", a um acroleto correspondendo à língua-base "oficial". As variações, em vez de se espalhar ao longo de um eixo orientado entre dois pólos, vão se repartir de maneira muito mais complexa, segundo eixos múltiplos, numa estrutura multipolar, considerando-se a imensa variedade das línguas de prestígio da região (inglês, malaio, mandarim, hokkien, hindi, e outras).

A sobrevivência da língua kristang em condições aparentemente tão adversas se deve portanto, na nossa opinião, em grande parte à existência dessa língua de marujos e de comerciantes, o pidgin português em uso nessas regiões. É preciso porém acrescentar outro fator cultural, que é o da religião. A comunidade kristang minoritária reflete todos os traços de uma sociedade sitiada, que se apega aos valores que the conferem originalidade e a distinguem das massas que a cercam. Logo, nada extraordinário se essa minoria funde num só

5 BICKERTON, D. On the supposed "gradualness" of creole development. In: Journal of Pidgin and Creole Languages 6:1. Amsterdam, Jonh Benjamins Publishing Company, 1992. O autor considera que cada falante ou grupo de falantes realiza uma variante do crioulo que representa um elemento de um leque de falares que se estende da língua que originou o léxico - no caso, o português - até o crioulo mais distante da língua fonte; em outros termos, este leque constitui um continuum que se estende entre dois pólos, ou seja, duas línguas “puras': a língua fonte, dita acroleto, que forneceu a base lexical do crioulo, e a língua crioula propriamente dita, ou basileto, que se distingue radicalmente da primeira pela sua estrutura sintática e morfológica. 
vocábulo, o kristang, as garantias da sua identidade, ou seja, língua e religião. Tal foi a situação em Malaca, quando os portugueses, vencidos pelos holandeses em 1641, abandonaram a população kristang aos protestantes batavos.

Aparentemente, não se encontra a mesma crispação nas comunidades kristang de Malaca que fugiram para o reino de Sião, onde parece que se fundiram rapidamente com as populações locais, tanto em Phuket, como em Ayutthaya e em Bangkok. Como as terras budistas se revelaram com certeza mais tolerantes, os exilados de Malaca, apesar de conservarem a sua religião, adotaram rapidamente a língua e os costumes da sua nova pátria. Os documentos conhecidos a esse respeito são raros, as pesquisas inexistem até hoje, de modo que ainda ficamos apenas em conjeturas. Porém, podemos esperar que um dia saberemos mais sobre a vida da comunidade "portuguesa" de Ayutthaya", por exemplo, já que a sua existência é atestada pelos vestígios de uma igreja da qual subsistem os alicerces, assim como um cemitério.

A Birmânia deveria também se revelar um campo de pesquisa fértil, tanto na área das escavações arqueológicas, como na da pesquisa de arquivos ${ }^{7}$. Com efeito, a existência de comunidades "portuguesas" também é atestada aí, embora não se conheça a real origem étnica dessas comunidades, porque a apelação "portuguesa" naqueles tempos era aplicada de modo indiscriminado, tanto aos súditos de Portugal, quanto aos convertidos católicos. Entretanto, podemos supor que um certo número desses "portugueses" eram kristangs de Malaca.

Uma parte dos kristangs foi levada como prisioneiros de guerra para Batávia, a nova capital da Companhia das Índias Holandesas. Reduzidos à condição de escravos, foram porém libertados em troca da sua conversão à religião reformada. A esses "portugueses pretos" , como eram chamados por causa da cor habitual das suas roupas, foi atribuída fora das fortificações uma grande igreja, cuja parte externa é de um sóbrio estilo calvinista, enquanto a decoração interna, deixada por conta dos fiéis, demonstra uma exuberância toda

6 Ayutthaya foi a antiga e imensa capital de Sião, até o final do século XVIII, quando foi totalmente destruída pelos birmaneses; a cidade nunca mais foi reconstruída e foi substituída por uma nova capital, $100 \mathrm{~km}$ rio abaixo, chamada Krung Thep, que para os ocidentais é Bangkok.

$7 \mathrm{O}$ historiador Jorge Morebey, que foi adido cultural na embaixada de Portugal na Tailândia no final dos anos 1990, estava acumulando um grande número de dados a respeito das comunidades "portuguesas" esquecidas e desaparecidas na Tailândia e na Birmânia. 
barroca. Trata-se, provavelmente, de um caso raro no mundo, o de um templo protestante barroco, que se pode visitar hoje em dia na parte antiga da cidade de Jacarta. Entre os "portugueses", os anjinhos conviviam ainda em paz com a austeridade da sua nova confissão.

Há uns trinta anos, ainda era possível encontrar os descendentes de "portugueses" falando esse crioulo português de Java, pois estes últimos representantes da comunidade haviam-se fixado no subúrbio de Tugu, próximo do porto de Tanjung Priok, em Jacarta. Os documentos a respeito são raros e na sua maioria datam de mais de um século, da época da pesquisa de Schuchardt ${ }^{8}$. No entanto, foi conservada uma amostra bastante ampla de canções coletadas nos anos 1950.

A ilha de Flores é povoada por uma ampla maioria católica, assim como as pequenas ilhas das redondezas, como Solor ou Adonara,. Quase todos os patrônimos são portugueses, inclusive os dos pequenos reis locais ou, melhor, dos seus descendentes atuais. Assim, o rajá (Senhor ou soberano tradicional local) da cidade de Sikka se chama Dom Sentis Alexius da Silva, e nomes semelhantes podem ser encontrados em Larantuka ou em Maumere, com as famílias Dias, Vieira, Godinho, Belteran, entre outras. Nenhuma língua crioula é falada nos dias de hoje, porém, por outro lado, essa mesma língua crioula que já se tornou incompreensível para os participantes, uma língua aureolada de mistério, assim como o latim para o fiel dos países ocidentais, é ainda conservada pelas irmandades religiosas em algumas das suas cerimônias em orações, cantos ou dramas próximos dos nossos mistérios medievais, que não deixam de apresentar assim um certo status, o de língua sacra, pois, com efeito, a língua do divino não poderia ser a do cotidiano. Um grande número de obras sacras é conservado e venerado pelos membros dessas irmandades, que dificilmente permitem que sejam admiradas por estrangeiros.

A ilha vizinha de Solor conserva as ruínas de uma fortaleza portuguesa que controlava o estreito ligando o mar das Célebes com o Oceano Índico. Ironicamente, o forte se encontra hoje em dia no centro da única vila muçulmana de Solor. Hoje há um kampong ${ }^{9}$ instalado no interior dos muros da fortaleza,

8 SCHUCHART, Hugo. Pidgins and Creole Languages. Selected essays. London, Cambridge University Press, 1980.

9 Designa um vila rural no mundo malaio (tanto na Indonésia como na Malásia). 
invadida pelas figueiras-da-Índia, onde canhões enferrujados testemunham a importância estratégica de outrora.

Timor-Leste apresenta um quadro bastante diferente, na medida em que permaneceu na condição de colônia portuguesa, mantendo portanto a presença da língua-base, o português. Uma língua crioula pode ter se desenvolvido, porém deixou de existir atulamente. Alan Baxter ${ }^{10}$ assinala uma comunidade num subúrbio de Dili que falaria, ou teria falado, uma língua apresentando todas as características de uma língua crioula. Será um falar remanescente de um antigo crioulo próprio de Timor, ou descendente do kristang? Essa pergunta ameaça ficar sem resposta para sempre.

Como já dissemos, a Tailândia, ou, para não cometer anacronismo, o Sião, se mostrou muito acolhedor para os refugiados "portugueses", incentivando a sua assimilação, porém garantindo a liberdade religiosa. Entretanto, a administração os obrigou a adotar nomes oficiais tailandeses, de modo que se tornou praticamente impossível retratar a história desses exilados luso-kristangs sem recorrer ao exame dos arquivos do reino ou das paróquias, tarefa só recentemente empreendida pelo Sr. Morebey. A mesma investigação teria que ser feita no que diz respeito às comunidades estabelecidas na Birmânia, das quais algumas teriam a sua origem em feudos fundados no século XVI em Araken, por aventureiros portugueses tornados reis ao reconhecerem como suseranos os reis locais.

As escavações arqueológicas já trouxeram à luz do dia em Ayuthaya o sítio concedido pelo rei de Sião aos portugueses (e, talvez, aos exilados kristangs). A cidade de Ayutahaya era a capital do reino de Sião, com uma população considerável e rica, contando com inúmeros e suntuosos templos e palácios. À beira do rio Chao Praya, a cidade, que pelo seu esplendor tanto espantava os visitante ocidentais, foi arrasada pelos invasores birmaneses no fim do século XVIII, o que motivou a fundação da nova capital, uma centena de quilômetros rio abaixo. Os portugueses haviam sido os primeiros europeus que iniciaram relações diplomáticas e comerciais com os siameses, e obtiveram o privilégio de estabelecer um bairro próprio em Ayuthaya, com igreja e cemitério, cujos vestígios foram recentemente exumados com o apoio da Fundação Gulbenkian

10 BAXTER, Alan. A grammar of kristang. Canberra:Pacific Linguistics, 1988. 
e sob os auspícios do governo da Sua Majestade, o Rei da Tailândia. Porém, sem um trabalho paralelo de estudo de arquivos, será difícil traçar o retrato dessa comunidade bem como determinar a sua composição.

Finalmente, para encerrar esta visão rápida do destino da primeira diáspora luso-kristang, é preciso lembrar que os exilados contribuíram para a fundação da primeira cidade na ilha de Pinang, que até então era povoada unicamente por pescadores e camponeses malaios, agrupados em pequenas vilas. Com esses exilados é que começa a se realizar a vocação comercial da ilha, que vai se acelerar no século XVIII com a chegada dos britânicos, que ali fundaram um dos seus Straits Settlements, com a cidade de Georgetown, hoje a segunda cidade da Malásia em importância. Os descendentes católicos desses exilados kristangs se concentram até hoje nos arredores do local do seu primeiro estabelecimento, no bairro de Pulau Tikus.

\section{Contatos e empréstimos lingüísticos}

A queda de Malaca nas mãos dos holandeses é menos o resultado de uma guerra sem piedade contra os portugueses do que a convicção adquirida aos poucos pelos dois lados de que, para essas potências relativamente pequenas, era melhor concentrar o esforço colonial em determinadas regiões de modo a enfrentar a concorrência perigosa das grandes potências emergentes como a Inglaterra, a Espanha ou a França. Houve certamente muitas batalhas e os portugueses tiveram que desistir das suas ambições no mundo malaio, enquanto que os holandeses renunciaram a suas conquistas no Brasil, na província de Pernambuco. Assim, essas retiradas se inscreviam numa política racional de colonização que implicava numa divisão das tarefas comerciais das nações mercantis.

É preciso igualmente lembrar que Portugal passou por uma época difícil, durante a qual a sua própria identidade enquanto nação foi ameaçada, quando a coroa foi reunida à da Espanha e a metrópole ocupada pelos espanhóis durante 60 anos, de 1580 a 1640. De fato, os verdadeiros adversários dos holandeses eram historicamente muito mais os espanhóis do que os portugueses, tanto na Europa como na Ásia, de modo que, apesar das escaramuças, essas duas pequenas nações de comerciantes tinham que ser antes aliadas do que inimigas. 
Como já foi dito acima, a presença dos portugueses, no século XVI, nas águas dos mares da China e no mundo malaio, deixará nessas regiões marcas profundas, que vão permanecer muito depois da retirada de Portugal. A língua portuguesa, na sua forma pidginizada, se mantém até o início do século XIX, quando será substituída pelo inglês como língua de intercâmbio.

A esse respeito, é interessante notar que os dialetos das Índias neerlandesas, ou seja, da Indonésia atual, são quase totalmente isentos de empréstimos lingüísticos holandeses, embora a Holanda tenha sido a potência colonial que administrou o arquipélago durante mais de três séculos. Em compensação, os empréstimos lexicais do português representam um número considerável. Pessoalmente, levantamos, em bahasa indonesia um conjunto de cerca de 200 palavras de origem portuguesa, de uso corriqueiro e generalizado atualmente. Além do mais, a lista aumenta de maneira considerável quando se leva em conta os falares malaios locais, como os de Manado, nas Célebes, de Ambom, nas Molucas, de Timor ou de Sangir. Os mesmos empréstimos se encontram em bahasa malaysia, língua oficial da Malásia. Vejamos aqui imediatamente alguns exemplos:

\begin{tabular}{|l|l|l|}
\hline alavanca & $>$ & alabangka \\
\hline armário & $>$ & lemari / almari \\
\hline bacia & $>$ & basi \\
\hline balde & $>$ & baldi \\
\hline bandeira & $>$ & bendera \\
\hline bóia & $>$ & boya \\
\hline bola & $>$ & bola \\
\hline bolo & $>$ & bolu \\
\hline bomba & $>$ & bomba \\
\hline boneca & $>$ & boneka \\
\hline camisa & $>$ & kemeja \\
\hline carreta & $>$ & kereta \\
\hline couve & $>$ & kubis \\
\hline dado & $>$ & buah dadu \\
\hline domingo & $>$ & hari minggu \\
\hline escola & $>$ & sekolah \\
\hline festa & $>$ & pesta \\
\hline fita & $>$ & pita \\
\hline garfo & $>$ & garpu \\
\hline igreja & & gereja \\
\hline & & \\
\hline
\end{tabular}




\begin{tabular}{|l|c|r|}
\hline inteiro & $>$ & antero \\
\hline janela & $>$ & jendela \\
\hline leilão & $>$ & lelang / lelong \\
\hline manteiga & $>$ & mentega \\
\hline mesa & $>$ & meja \\
\hline prumo & $>$ & perum \\
\hline queijo & $>$ & reju \\
\hline renda & $>$ & hari sabtu \\
\hline sábado & $>$ & sepatu \\
\hline sapato & $>$ & serdadu \\
\hline soldado & $>$ & tempoh \\
\hline tempo & $>$ & tuala \\
\hline toalha & $>$ & terigu \\
\hline trigo & &
\end{tabular}

A respeito desses empréstimos lingüísticos, podemos notar que são exclusivamente de natureza lexical, como aliás é a regra na primeira etapa de contatos lingüísticos. A amplidão e a diversidade dos campos semânticos nos quais os empréstimos se realizaram testemunham a importância dos intercâmbios históricos entre o mundo malaio e os navegadores portugueses. É preciso observar que tais intercâmbios não operaram numa direção só, pois palavras como lancha, chávena, jambo, bule, gongo, rotim, sagú, etc., provém das línguas malaias, assim como grande quantidade de nomes relativos à botânica e à zoologia.

Não consta, pelo menos no nosso conhecimento, nenhum estudo sério sobre contatos lingüísticos entre o português e línguas como o tailandês ou o birmanês. Se os empréstimos mútuos não se revestiram da mesma amplitude que constatamos no caso das línguas malaias, devem no entanto ter tido uma certa importância, embora talvez poucos tivessem sobrevivido ao fim dos intercâmbios comerciais e diplomáticos. Não deixa de ser notável o fato de uma palavra tão importante para a cultura tailandesa como sala ser de origem portuguesa, palavra que designa um elemento indispensável no mundo religioso budista, a sala de reunião no seio do complexo formado pelo templo tradicional.

Tentamos pintar aqui um quadro conciso daquilo que sobreviveu da epopéia relativamente breve de Portugal no Sudeste da Ásia. Essa aventura, embora efêmera, deixou nas culturas da região marcas duráveis, definitivas até, pelo fato 
de os portugueses terem chegado mais cedo. Poderíamos também lembrar a sua relativa tolerância e a sua capacidade de integração, provavelmente maior do que a dos outros europeus da época. O fato de Portugal ter uma população pequena demandava uma política de integração e de casamentos interétnicos, o que era inimaginável para as outras nações colonialistas européias. Tal é a explicação que freqüentemente se oferece para dar conta da importância do fenômeno crioulo nos contratos entre portugueses e povos do ultramar. Porém, essa área de investigações permanece ainda relativamente virgem e, com certeza, muitos dados estão à espera do seu descobrimento. Um dos objetivos deste artigo é realmente suscitar a eventual curiosidade de pesquisadores, apesar da relativa superficialidade da abordagem que foi a nossa.

\section{Referências bibliográficas:}

BARBOSA, Jorge Morais. A língua portuguesa no mundo. $2^{\mathrm{a}}$ ed. Ver. Lisboa: Agência Geral do Ultramar, 1969.

BARROS, João de. As Décadas da Ásia. Lisboa: Sá da Costa, 1945. reed.

BARROS, João de. Diálogo em louvor da nossa linguagem. Modena, 1959; edição organizada por Luciana Stegagno-Picchio.

BATALHA, Graciete N. Situação e perspectivas do Português e dos Crioulos de origem portuguesa na Ásia Oriental (Macau, Hong Kong, Malaca, Singapura, Indonésia). In Actas do Congresso sobre a situação actual da língua portuguesa no mundo. Lisboa: Instituto de Cultura e Língua Portuguesa, 1985.

BAXTER, Alan. A grammar of Kristang. Canberra: Pacific Linguistics, 1988.

COELHO, F. Adolpho. Os dialectos românicos ou neo-latinos na África, Ásia e América. Lisboa: Boletim da Sociedade de Geografia, 1883.

DALGADO, Sebastião R. Dialecto indo-português de Ceylão. Lisboa: Imprensa Nacional, 1900.

FRANÇA, António Pinto da. Portuguese Influence in Indonesia. Lisboa: Fundação Callouste Gulbenkian, 1985.

GUISAN, Pierre. Línguas em contato no sudeste da Ásia. O caso do kristang. Rio de Janeiro: UFRJ, 1992. Dissertação de Mestrado.

HAAN, Dr. F. de. Oud Batavia. Batavia : Société des Arts et Sciences de Batavia, 1919. 
LOPES, David de Melo. A expansão da língua portuguesa no oriente durante os séculos XVI, XVII e XVIII. Barcelos : Portucalense Editora, 1936.

MARRE. Notice sur la langue portugaise dans l'Inde française et en Malaisie. In : Annales de l'Extrême-Orient, 1881.

PIRES, Tomé. A Suma Oriental. Coimbra: Acta Universitatis Conimbrigensis, 1978.

REGO, Pe. António da S. Dialecto português de Malaca. Apontamentos para o seu estudo. Lisboa: Agência Geral da Colónias, 1942.

SANTA MARIA, Luigi. I prestiti portoghesi nel Malese-Indonesiano. Napoli: Istituto Orientale di Napoli,1967.

SCHUCHARDT, Hugo. Pidgins and Creole Languages. Selected Essays. London: Cambridge University Press, 1980.

SANTA MARIA, Bernard. My people, my country. Malaca: Malaca Portuguese Development Centre, 1982.

THOMAZ, Luís Felipe. A língua portuguesa em Timor. In: Actas do Congresso sobre a situação actual da língua portuguesa no mundo. Lisboa: Instituto de Cultura e de Língua Portuguesa, 1985.

VIANA, Gonçalves. Vocabulário malaio derivado do português. In: Revista Lusitana, Lisboa, tomo VIII, 1902-1904. 